Accepted Manuscript. The final article was published in: Chemical Communications, 2011, 47, 3401-3403 and is available at: https://doi.org/10.1039/C1CC10237K

\title{
Syntheses and Structures of Triazides of Heavy Group 15 Elements
}

\author{
Stephan Schulz, ${ }^{*, a}$ Benjamin Lyhs, ${ }^{a}$ Georg Jansen, ${ }^{a}$ Dieter Bläser ${ }^{\mathrm{a}}$ and Christoph Wölper ${ }^{\mathrm{a}}$ \\ Received (in $X X X, X X X)$ Xth $X X X X X X X X X 20 X X$, Accepted Xth $X X X X X X X X X 20 X X$ \\ DOI: 10.1039/b000000x
}

${ }_{5}$ Synthesis of group 15-triazides $\mathrm{E}\left(\mathrm{N}_{3}\right)_{3}(\mathrm{E}=\mathrm{Sb} 1, \mathrm{Bi} 2)$ and $\mathrm{Py}_{2}-\mathrm{Bi}\left(\mathrm{N}_{3}\right)_{3} 3(\mathrm{Py}=$ pyridine). Single crystals of 1 were in situ grown by a IR-laser-assisted technique on the diffractometer. The structure of 3 , which represents the first structurally characterized neutral Bi-triazide, is influenced by crystal ${ }_{10}$ packing effects according to DFT calculations.

Neutral binary group 15 azides of the types $\mathrm{E}\left(\mathrm{N}_{3}\right)_{3}$ and $\mathrm{E}\left(\mathrm{N}_{3}\right)_{5}$ have been intensely studied over the last decades. While phosphorous triazide could be neither isolated nor structurally characterized and phosphorous pentaazide is still unknown, to 15 date,[1] the corresponding complexes of the heavier group 15 elements, $\mathrm{As}\left(\mathrm{N}_{3}\right)_{3},[2] \mathrm{As}\left(\mathrm{N}_{3}\right)_{5},[3] \mathrm{Sb}\left(\mathrm{N}_{3}\right)_{3}[2 \mathrm{~b}, 4]$ and $\mathrm{Sb}\left(\mathrm{N}_{3}\right)_{5}[3]$ have been synthesized within the last few years. Moreover, thermally more stable ionic complexes containing anions of the types $\mathrm{E}\left(\mathrm{N}_{3}\right) 4^{-}(\mathrm{E}=\mathrm{As}, \mathrm{Sb})[5]$ and $\mathrm{E}\left(\mathrm{N}_{3}\right) 6^{-}(\mathrm{E}=\mathrm{P},[6] \mathrm{As},[5,7]$ $\left.{ }_{20} \mathrm{Sb}[5,3]\right)$ as well as cations $\mathrm{E}\left(\mathrm{N}_{3}\right) 4^{+}(\mathrm{E}=\mathrm{P},[8] \mathrm{As},[5] \mathrm{Sb}[5])$ have been synthesized and isolated. Very recently, Schulz et al. synthesized the first neutral and anionic bismuth azides $\mathrm{Bi}\left(\mathrm{N}_{3}\right)_{3}$, (thf)Bi( $\left(\mathrm{N}_{3}\right)_{3}, \mathrm{Bi}\left(\mathrm{N}_{3}\right)_{4}{ }^{-}$and $\mathrm{Bi}\left(\mathrm{N}_{3}\right)_{6}{ }^{3-}$.[9] Even though these binary complexes, which are typically heat and shock-sensitive 25 compounds, have been well characterized by means of IR and Raman spectroscopy, informations on their structures in the solid state are still rather scarce. To date, only $\mathrm{As}\left(\mathrm{N}_{3}\right)_{3},[2 \mathrm{a}]$ $\left.\mathrm{Sb}\left(\mathrm{N}_{3}\right)_{3},[2 \mathrm{a}] \mathrm{P}\left(\mathrm{N}_{3}\right) 6^{-},[10] \mathrm{As}\left(\mathrm{N}_{3}\right)_{6},{ }^{-},{ }^{-}\right] \mathrm{Sb}\left(\mathrm{N}_{3}\right) 6_{6}^{-},[3] \mathrm{Bi}\left(\mathrm{N}_{3}\right)_{4}^{-},[9]$ and $\mathrm{Bi}\left(\mathrm{N}_{3}\right)_{6}{ }^{3-}[9]$ have been structurally characterized.

30 Herein, we report on a slightly modified route for $\mathrm{E}\left(\mathrm{N}_{3}\right)_{3}(\mathrm{E}=$ $\mathrm{Sb} \mathrm{1}, \mathrm{Bi} 2)$ and the synthesis of $\mathrm{Py}_{2}-\mathrm{Bi}_{(}\left(\mathrm{N}_{3}\right)_{3}$ 3. 1 - 3 were characterized by NMR $\left({ }^{14} \mathrm{~N}\right)$, IR and Raman spectroscopy, $\mathbf{1}$ and $\mathbf{3}$ also by single crystal X-ray diffraction. 3 represents the first structurally characterized Lewis-base stabilized bismuth azide.

$$
\begin{gathered}
\mathrm{EF}_{3}+\mathrm{Me}_{3} \mathrm{SiN}_{3}(\text { ex. }) \underset{-3 \mathrm{Me}_{3} \mathrm{SiF}}{\longrightarrow} \mathrm{E}\left(\mathrm{N}_{3}\right)_{3}(\mathrm{E}=\mathrm{Sb} \text { 1, Bi 2) } \\
\mathrm{Bi}\left(\mathrm{N}_{3}\right)_{3} \frac{\text { pyridine, } \mathrm{CH}_{2} \mathrm{Cl}_{2}}{-30^{\circ} \mathrm{C}}-\mathrm{Py}_{2}-\mathrm{Bi}\left(\mathrm{N}_{3}\right)_{3} 3 \\
\text { Scheme } 1 \text { Synthesis of } 1-3
\end{gathered}
$$

1 and 2 were synthesized by reaction of $\mathrm{SbF}_{3}$ and $\mathrm{BiF}_{3}$, respectively, with an excess of $\mathrm{Me}_{3} \mathrm{SiN}_{3}$ in the absence of any additional organic solvents. 3 was obtained by re-crystallization 40 from a solution of 2 in $\mathrm{CH}_{2} \mathrm{Cl}_{2}$ and pyridine at $0{ }^{\circ} \mathrm{C}$. The ${ }^{14} \mathrm{~N}$ NMR spectrum $\left(25^{\circ} \mathrm{C}\right)$ of a solution of 1 in $\mathrm{CH}_{2} \mathrm{Cl}_{2}$ shows three well-resolved resonances due to the azido groups at $-321\left(\Delta v_{1 / 2}=\right.$ $170 \mathrm{~Hz}\left(\mathrm{~N}_{\alpha}\right),-134\left(\Delta v_{1 / 2}=26 \mathrm{~Hz}\left(\mathrm{~N}_{\beta}\right)\right.$ and $-169 \mathrm{ppm}\left(\Delta v_{1 / 2}=34\right.$
$\mathrm{Hz}\left(\mathrm{N}_{\gamma}\right)$, respectively. These resonances are in accord with 45 experimental values reported previously[2b,4] and correspond very well with typical values of covalently bound azido groups. The ${ }^{14} \mathrm{~N}$ NMR spectrum of a solution of $\mathbf{2}$ in $\mathrm{CH}_{2} \mathrm{Cl}_{2}$, which was not reported in the original contribution by Schulz et al. due to the low solubility of $\mathbf{2}$ in organic solvents,[9] shows comparable 50 resonances for $\mathrm{N}_{\alpha}\left(\delta=-324, \Delta v_{1 / 2}=140 \mathrm{~Hz}\right), \mathrm{N}_{\beta}(\delta=-135$, $\Delta v_{1 / 2}=20 \mathrm{~Hz}$ and $\mathrm{N}_{\gamma}\left(\delta=-170, \Delta v_{1 / 2}=32 \mathrm{~Hz}\right)$. Almost analogous values were observed for a solution of $\mathbf{3}$ in $\mathrm{CH}_{2} \mathrm{Cl}_{2}$, showing the expected resonances due to the azide groups $(\delta=-$ $325, \Delta v_{1 / 2}=580 \mathrm{~Hz}\left(\mathrm{~N}_{\alpha}\right) ;-135, \Delta v_{1 / 2}=25 \mathrm{~Hz}\left(\mathrm{~N}_{\beta}\right) ;-172, \Delta v_{1 / 2}$ $\left.{ }_{55}=480 \mathrm{~Hz}\left(\mathrm{~N}_{\gamma}\right)\right)$ and an additional resonance of the pyridine Lewis bases at $-66 \mathrm{ppm}\left(\Delta v_{1 / 2}=120 \mathrm{~Hz}\right)$. IR and Raman spectra of $\mathbf{1}$ and 2 correspond very well with those previously reported[2b,4,9,11]. 3 shows strong adsorption bands due to the asymmetric (IR: $v=2039,2021 \mathrm{~cm}^{-1}$; Raman: $v=2095,2044$ ${ }_{60} \mathrm{~cm}^{-1}$ ) and symmetric N-N-N stretching mode (IR: $v=1316,1253$ $\mathrm{cm}^{-1}$; Raman: $\left.v=1327,1274 \mathrm{~cm}^{-1}\right)$ and the N-N-N deformation mode (IR: $v=642,593 \mathrm{~cm}^{-1}$; Raman: $v=650 \mathrm{~cm}^{-1}$ ).

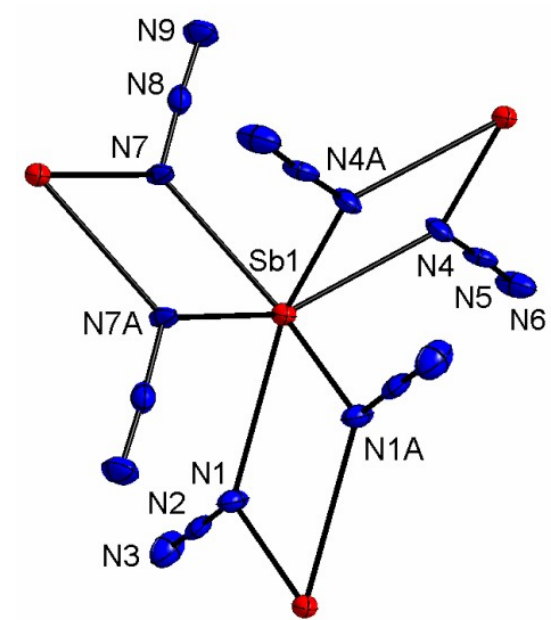

Fig. 1 Solid state structure of 1 showing the intermolecular coordination 65 mode.

Single crystals of $\mathbf{1}$ were grown by a IR-laser-assisted technique in an open quartz glass capillary under an inert nitrogen atmosphere directly on the diffractometer. The IR-laser allowed a very controlled heating of the sample, hence allowing 70 optimization of the growth conditions, in which the sample sublimizes without considerable decomposition. The successful growth of suitable crystals of $\mathbf{1}$ clearly demonstrates the promising potential of this method even for the structural 
characterization of heat- and shock-sensitive complexes.

1 is the second polymorph of $\mathrm{Sb}\left(\mathrm{N}_{3}\right)_{3}$ as was verified by checking the elemental cell of $\mathbf{1}$ at $223 \mathrm{~K}$ and at ambient temperature. No signs of a phase transition was found in this 5 temperature regime. The initially reported structure $\left(\mathbf{1}^{\prime}\right)$, which was determined at $223 \mathrm{~K}$,[2b] was found to crystallize as perfect $\mathrm{C}_{3}$ symmetric molecule, whereas $\mathbf{1}$ crystallizes in the triclinc space group P-1 with one molecule in the asymmetric unit. The central $\mathrm{Sb}$ atom in $\mathbf{1}$ is sixfold coordinated by (asymmetrically)

10 bridging azido groups as was previously observed. The azide units are almost linear with N-N-N bond angles between 177.4(6) and $178.5(6)^{\circ}$ and the $\mathrm{Sb}-\mathrm{N}$ bond lengths range from 2.119(5) to 2.151(5) $\AA$. These values differ only slightly from those reported for $1^{\prime}\left(\mathrm{N}-\mathrm{N}-\mathrm{N}\right.$ 178.3(5) ${ }^{\circ}$; Sb-N 2.119(4) $\AA$ ) and $\mathrm{SbCl}\left(\mathrm{N}_{3}\right)_{2}$ $15\left(177(1), 178.8(9)^{\circ}\right) \cdot[12]$ The $\mathrm{N}_{\alpha}-\mathrm{N}_{\beta}$ bond lengths in 1 (N1-N2 1.231(7); N4-N5 1.248(7); N7-N8 1.235(7) $\AA$ ) are longer than the $\mathrm{N}_{\beta}-\mathrm{N}_{\gamma}$ bond lengths (N2-N3 1.125(7); N5-N6 1.128(7); N8-N9 $1.133(8) \AA)$ as was observed for 1' (1.233(6), 1.131(6) $\AA$ ) and other $\mathrm{Sb}(\mathrm{III})$ azides $\left(\mathrm{SbCl}\left(\mathrm{N}_{3}\right)_{2} 1.22(1), 1.13(1) \AA,[13]\left[\mathrm{N}_{3} \mathrm{Sb}(\mu-\right.\right.$ $\left.\left.{ }_{20} \mathrm{~N} t-\mathrm{Bu}\right)\right]_{2}$ 1.222(5), 1.133(5) $\AA,[14]\left[t-\mathrm{BuC}(\mathrm{N} i-\mathrm{Pr})_{2}\right] \mathrm{Sb}\left(\mathrm{N}_{3}\right)_{2}$ av. values 1.216(2), 1.143(2) $\AA[15])$ and $\mathrm{Sb}(\mathrm{V})$ azides $\left(\mathrm{Ph}_{4} \mathrm{SbN}_{3}\right.$ 1.198(4), 1.150(4) $\AA,[16]\left[\mathrm{Ph}_{4} \mathrm{P}\right]\left[\mathrm{Sb}\left(\mathrm{N}_{3}\right)_{6}\right]$ av. values 1.22 and $1.12 \AA[3])$, respectively. The structures of $\mathbf{1}$ and $\mathbf{1}$ ' are quite similar. The "Mitsubishi emblem-type"[2b] pattern of $\mathrm{Sb} \cdots \mathrm{N}_{\alpha}$ 25 interactions in $\mathbf{1}^{\prime}$ ' was also found in the structure of $\mathbf{1}$. However, the secondary interactions in 1 range from 2.659(5) $\AA$ to 2.819(5) $\AA$, whereas they are are equidistant in 1' (symmetry equivalence; $2.844 \AA$ ). Despite the shorter interactions as observed for $\mathbf{1}$, the densities of $\mathbf{1}$ and 1' are almost equal (1: $2.81 ; \mathbf{1}^{\prime}$ : 2.83 both at $30223 \mathrm{~K})$. The crystallographic data alone therefore do not allow a decision on which polymorph is the thermodynamically more stable one. The structures differ in the way the layers are related. In 1 they are equivalent via translation parallel to the b-axis, while in $\mathbf{1}^{\prime}$ they are related via inversion.

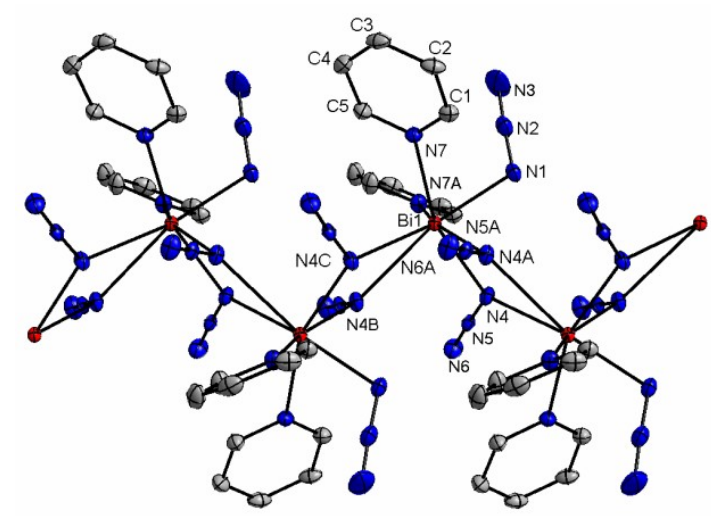

Fig. 2 Solid state structure of $\mathbf{3}$ showing the chain-like structure; $\mathrm{H}$ atoms are omitted for clarity.

Single crystals of $\mathbf{3}$ suitable for an $\mathrm{X}$-ray structure determination were obtained from a solution of $\mathbf{3}$ in $\mathrm{CH}_{2} \mathrm{Cl}_{2}$ and ${ }_{40}$ pyridine after storage at $0{ }^{\circ} \mathrm{C}$ for $48 \mathrm{~h}$. 3 crystallizes in the orthorhombic noncentrosymmetric space group $\mathrm{Cmc} 2{ }_{1}$ with four independent molecules in the unit cell. The absolute structure was determined by refinement of the Flack parameter to -0.001 , with a standard uncertainty of 0.006.[17] The asymmetric unit consists 45 of one pyridine ligand, one azido ligand on a general position and one placed in the mirror plane as well as a central $\mathrm{Bi}$ atom, which is also located in the mirror plane. As a consequense, the $\mathrm{Bi}$ atom in $\mathbf{3}$ is coordinated by two pyridine bases and three azido ligands with that on the special position adopting a terminal binding ${ }_{50}$ mode. The remaining two azido groups serve as (asymetrically) bridging groups (through $\mathrm{N}_{\alpha}$ ), resulting in the formation of an endless chain structure constituted by 21 symmetry. Each Bi atom adopts a sevenfold coordination geometry.

To the best of our knowledge, $(\mathrm{Py})_{2} \mathrm{Sb}\left(\mathrm{N}_{3}\right) \mathrm{Cl}_{2}$ represents the 55 only structurally characterized group 15 element azide complex that is coordinated by two additional Lewis bases.[18] However, this complex consists of isolated molecules as was observed recently for [2-( $\left.\left.\mathrm{Me}_{2} \mathrm{NCH}_{2}\right) \mathrm{C}_{6} \mathrm{H}_{4}\right] \mathrm{Bi}\left(\mathrm{N}_{3}\right)_{2}$.[19] In contrast, [2$\left.\left(\mathrm{Me}_{2} \mathrm{NCH}_{2}\right)_{6} \mathrm{C}_{4}\right]_{2} \mathrm{Bi}\left(\mathrm{N}_{3}\right)$ [19] forms a dimer in the solid state 60 whereas $\mathrm{Me}_{2} \mathrm{BiN}_{3}$ adopts a polymeric $\mathrm{N}_{\alpha}$-bridged chain-like structure, in which each $\mathrm{Bi}$ atom is fourfold coordinated.[20] The azide groups in $\mathbf{3}$ differ only slightly from linearity (N1-N2-N3 177.4(5), N4-N5-N6 176.8(2) ${ }^{\circ}$ and the $\mathrm{N}_{\alpha}-\mathrm{N}_{\beta}$ bonds (N1-N2 1.214(4); N4-N5 1.213(3) $\AA$ ) are longer than the $\mathrm{N}_{\beta}-\mathrm{N}_{\gamma}$ bonds 65 (N2-N3 1.138(5); N5-N6 1.148(3) $\AA$ ). The terminal bonded azide group shows the shortest Bi-N bond length (Bi1-N1 2.277(3) $\AA$ ), whereas the $\mathrm{Bi}-\mathrm{N}$ bond length to the pyridine bases (Bi1-N7 $2.618(2) \AA$ ) is in between those observed for the bridging azide groups (Bi1-N4 2.304(2) Bi1-N4A 2.797(2) $\AA$ ). These values are 70 exactly within the range given by the sum of the single bond covalent radii $(2.22 \AA,[21] 2.16[22])$ and the sum of the van-derWaals radii (3.62 $\AA[22])$. A Cambridge structure database search revealed that $\mathrm{Bi}-\mathrm{N}$ bond lengths range from 2.10 to $2.90 \AA$ with an average distance of $2.50 \AA$, respectively. These structural 75 findings clearly indicate that the intermolecular $\mathrm{Bi}-\mathrm{N}_{\alpha}$ interaction is rather weak.

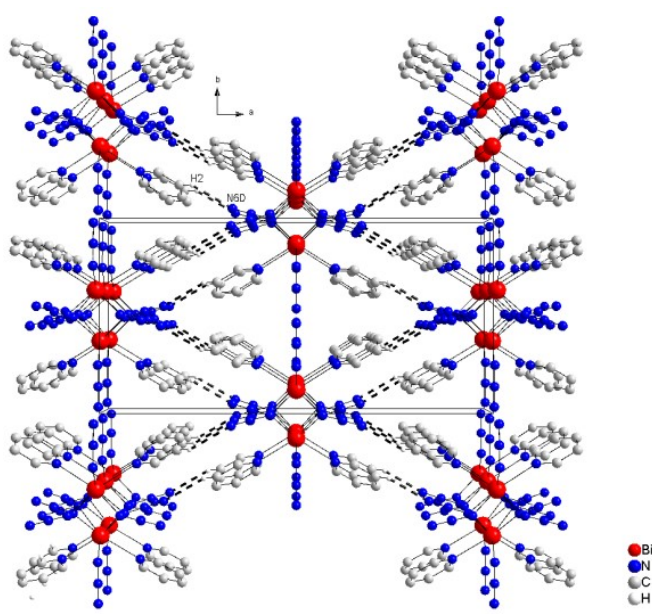

Fig. 3 Packing diagram of $\mathbf{3}$ showing the intermolecular hydrogen $\mathrm{C}$ $\mathrm{H} \cdots \mathrm{N}$ bridges.

80 As-formed chains show additional intermolecular $\mathrm{CH} \cdots \mathrm{N}$ hydrogen bridges to an adjacent chain (symmetry equivalent via $\mathrm{C}$ centring) through to interactions between $\mathrm{N} 6$ of bridging azides and $\mathrm{H} 2$ of the pyridine bases, resulting in the formation of a three dimensional network. $\mathrm{C} 2-\mathrm{H} 2 \cdots \mathrm{N} 6 \mathrm{D}$ shows typical distances and 85 angle of a non-classical hydrogen bond $(\mathrm{H} \cdots \mathrm{N} 2.59 \AA, \mathrm{CH} \cdots \mathrm{N}$ $\left.128.6^{\circ}\right)$, but the almost hexagonal arrangement $\left(52.9^{\circ}, 127.1^{\circ}\right.$ angles of the rhombus formed by adjacent chains) of the chains parallel to the c-axis suggests closest packing to be more 
important for the composition of this structure.

Density functional theory (DFT) calculations employing different exchange-correlation functionals, i.e. BP86 and B3LYP, in conjunction with a basis set of triple-zeta valence quality and a relativistic pseudopotential for $\mathrm{Bi}$ were carried out starting from the crystal structure of $\mathrm{Py}_{2}-\mathrm{Bi}\left(\mathrm{N}_{3}\right)_{3}$.[11] A monomeric unit $\mathrm{Py}_{2}-$ $\mathrm{Bi}\left(\mathrm{N}_{3}\right)_{3}$ was considered using all azide ligands with a $\mathrm{Bi}-\mathrm{N}$ distance below $2.62 \AA$. The resulting $\mathrm{Py}_{2}-\mathrm{Bi}\left(\mathrm{N}_{3}\right)_{3}$ unit displays $\mathrm{C}_{\mathrm{s}}$ symmetry, and geometry optimization followed by frequency 10 analysis shows a $\mathrm{C}_{\mathrm{s}}$-symmetrical structure to be a minimum at the BP86 level of theory as well. On the other hand, at the B3LYP level of theory the $\mathrm{C}_{\mathrm{s}}$-symmetrical structure is found to be a firstorder saddle point. The major difference between the calculated (BP86, B3LYP) and experimental structures is a rotation of those

15 azide groups, which adopt bridging positions in the solid state structure of $3(\mathrm{~N} 4, \mathrm{~N} 4 \mathrm{~A})$. The rotation brings the $\mathrm{N}_{\gamma}$ atoms of the azide groups closer to the pyridine ligands, in the case of B3LYP leading to a distance of about $2.98 \AA$, while with BP86 $2.83 \AA$ are found (in the following BP86 results are given in parentheses). 20 The azide groups differ slightly from linearity as was observed in the crystal structure of 3 . The N1-N2-N3 bond angle of the terminal azide group of $175.4^{\circ}\left(175.9^{\circ}\right)$ is comparable to that of the N4-N5-N6 group of $176.1^{\circ}\left(176.6^{\circ}\right)$ and the N1-N2 $(1.224$ $(1.215) \AA)$ and N4-N5 bond lengths (1.219 (1.212) $\AA$ ) agree very 25 well. Both are longer than the N2-N3 (1.154 (1.136) $\AA$ ) and N5N6 bond lengths (1.155 (1.138) $\AA$ ). Note that the B3LYP values are for the most part in excellent agreement with experimental values (vide supra). In contrast, the Bi-N distances (Bi-N1 2.235 (2.206), Bi-N4 2.247 (2.228), Bi-N7 2.822 (2.894) Å) differ more 30 notably from experiment. Geometry optimization of the pyridinefree triazide $\mathrm{Bi}\left(\mathrm{N}_{3}\right)_{3}$ leads to a $\mathrm{C}_{\mathrm{s}}$-symmetrical structure in which position and orientation of the azide ligands remain qualitatively unaltered. Frequency analysis shows this structure to be a secondorder saddle point at both levels of theory. Its energy is 3.8 (4.3)

$35 \mathrm{~kJ} / \mathrm{mol}$ above that of the $\mathrm{C}_{3}$-symmetrical minimum as found by Schulz et al.[9] and confirmed in calculations with our more extended basis set with both functionals, BP86 and B3LYP. A similar minimum structure was found for the $\mathrm{Py}_{2}-\mathrm{Bi}\left(\mathrm{N}_{3}\right)_{3}$ units upon distortion of the $\mathrm{C}_{\mathrm{s}}$-symmetrical structure along the 40 imaginary frequency mode found at the B3LYP level: after many geometry optimization steps one obtains a $\mathrm{C}_{1}$-symmetrical structure in which the two pyridine molecules coordinate to an essentially $\mathrm{C}_{3}$-symmetrical $\mathrm{Bi}\left(\mathrm{N}_{3}\right)_{3}$ group with $\mathrm{Bi}-\mathrm{N}$ distances of 2.78 and 2.81 (2.86 and 2.84) $\AA$, respectively, while the ortho $\mathrm{H}$ 45 atoms form hydrogen bridges to the $\mathrm{N}_{\alpha}$ atoms of the azide groups with lengths of 2.43 and 2.39 (2.46 and 2.48) $\AA$. The energy difference from the $\mathrm{C}_{\mathrm{s}}$-symmetrical structure to this minimum structure is $15.0(14.7) \mathrm{kJ} / \mathrm{mol}$, roughly $11 \mathrm{~kJ} / \mathrm{mol}$ larger than the corresponding energy difference in the free $\mathrm{Bi}\left(\mathrm{N}_{3}\right)_{3}$ complex. The 50 additional stabilization of the minimum structure can be most likely explained by a gain in hydrogen bonding energy. However, this small energy difference may easily be overcome by the effect of the two additional bridging azide groups with long $\mathrm{Bi}-\mathrm{N}$ bonds found in the crystal structure and by crystal packing effects.

\section{${ }_{55}$ Conclusions}

A neutral Bi-triazide was structurally characterized for the first time. Moreover, the promising potential of a specific IR-laser- assisted technique for the in situ growth of heat- and shocksensitive compounds on the diffractometer is demonstrated.

\section{${ }_{60}$ Notes and references}

${ }^{a}$ University of Duisburg-Essen, Universitätsstr. 5-7, S07 S03 C30, 45117 Essen, Germany. Fax: Int (+)201 1833830; Phone: Int (+)201 1834635; E-mail: stephan.schulz@uni-due.de.

$\dagger$ Electronic Supplementary Information (ESI) available: Full 65 experimental details and characterization of $\mathbf{1}$ - $\mathbf{3}$ including single crystal structures $(\mathbf{1}, \mathbf{3})$ and computational details $(\mathbf{3})$ are given in the suppporting information file. See DOI: 10.1039/b000000x/

\$ S.S. and B.L. gratefully acknowledge the Fonds der Chemischen Industrie (FCI) for financial support and a doctoral fellowship (B.L.).

70 Details of the crystal structure determination of $\mathbf{1}$ may be obtained from Fachinformationszentrum Karlsruhe, 76344 Eggenstein-Leopoldshafen, Germany (fax: +49-7247-808-666; e-mail: crysdata@fiz-karlsruhe.de,) on quoting the deposition number CSD-422405. CCDC-803386 contain the supplementary crystallographic data of complex 3 . These data can be 75 obtained free of charge from The Cambridge Crystallographic Data Centre via www.ccdc.cam.ac.uk/data_request/cif.

1 W. Buder and A. Schmidt, Z. Anorg. Allg. Chem. 1975, 415, 263; K. B. Dillon, A. W. G. Platt and T. C. Waddington, Inorg. Nucl. Chem. Lett. 1978, 14, 511. The photoelectron spectrum of $\mathrm{P}\left(\mathrm{N}_{3}\right)_{3}$ was

80 recently repported: X. Zeng, W.Wang, F. Liu, M. Ge, Z. Sun and D. Wang, Eur. J. Inorg. Chem. 2006, 416.

2 T. M. Klapötke and P. Geissler, J. Chem. Soc., Dalton Trans. 1995, 3365; R. Haiges, A. Vij, J. A. Boatz, S. Schneider, T. Schroer, M. Gerken and K. O. Christe, Chem. Eur. J. 2004, 10, 508; P. Geissler,

85 T. M. Klapötke and H.-J. Kroth, Spectrochim. Acta Part A 1995, 51, 1075.

3 R. Haiges, J. A. Boatz, A. Vij, V. Vij, M. Gerken, S. Schneider, T. Schroer, M. Yousufuddin and K. O. Christe, Angew. Chem. Int. Ed. 2004, 43, 6676

904 T. M. Klapötke, A. Schulz and J. McNamara, J. Chem. Soc. Dalton Trans. 1996, 2985.

5 K. Karaghiosoff, T. M. Klapötke, B. Krumm, H. Nöth, T. Schmitt and M. Suter, Inorg. Chem. 2002, 41, 170.

6 H. W. Roesky, Angew. Chem. Int. Ed. 1967, 6, 637; P. Volgnandt and A. Schmidt, Z. Anorg. Allg. Chem. 1976, 425, 189; R. Haiges, S. Schneider, T. Schroer and K. O. Christe, Angew. Chem., Int. Ed. 2004, 43, 4919; R. P. Singh, R. D. Verma, D. T. Meshri and J. M. Shreeve, Angew. Chem., Int. Ed. 2006, 45, 3584.

7 T. M. Klapötke, H. Nöth, T. Schmitt and M. Warchhold, Angew. Chem. Int. Ed. 2000, 39, 2108.

8 A. Schmidt, Chem. Ber. 1970, 103, 3923; W. Buder and A. Schmidt, Chem. Ber. 1973, 106, 3812.

9 A. Villinger and A. Schulz, Angew. Chem. Int. Ed. 2010, 49, 8017.

10 P. Portius, P. W. Fowler, H. Adams and T. Z. Todorova, Inorg. Chem. 2008, 47, 12004

11 Full details are given in the electronic supplement.

12 T. M. Klapötke, H. Nöth, T. Schütt and M. Warchold, Z. Anorg. Allg. Chem. 2001, 627, 81 .

13 The second azide group in $\mathrm{SbCl}\left(\mathrm{N}_{3}\right)_{2}$ showed somehow unrealistic N$\mathrm{N}$ distances of $0.98(1)$ and 1.28(1) $\AA$.

14 D. C. Haagenson, L. Stahl and R. J. Staples, Inorg. Chem. 2001, 40, 4491.

15 B. Lyhs, D. Bläser, C. Wölper and S. Schulz, Chem. Eur. J., accepted for publication.

11516 R. Haiges, T. Schroer, M. Yousufuddin and K. O. Christe, Z. Anorg. Allg. Chem. 2005, 631, 2691.

17 H. D. Flack, Acta. Cryst. A 1983, 39, 876 .

18 T. M. Klapötke, H. Nöth, T. Schütt and M. Suter, Eur. J. Inorg. Chem. 2002, 2511.

12019 A. Schulz and A. Villinger, Organometallics 2011, 30, 284.

20 J. Müller, U. Müller, A. Loss, J. Lorberth, H. Donath and W. Massa, Z. Naturforsch. 1985, 40b, 1320.

21 P. Pyykko and M. Atsumi, Chem. Eur. J. 2009, 15, 186.

22 Cambridge Structural database: http://www.ccdc.cam.ac.uk/products/csd/radii/table.php4 
DuEPublico

Duisburg-Essen Publications online
UNIVERSITÄT

offen im Denken

Ub | $\begin{aligned} & \text { universitäts } \\ & \text { bibliothek }\end{aligned}$

This text is made available via DuEPublico, the institutional repository of the University of Duisburg-Essen. This version may eventually differ from another version distributed by a commercial publisher.

DOI: $\quad 10.1039 / \mathrm{C} 1 \mathrm{CC} 10237 \mathrm{~K}$

URN: urn:nbn:de:hbz:464-20201110-102153-7

Accepted Manuscript. The final article was published in: Chemical Communications, 2011, 47, 3401-3403 and is available at: https://doi.org/10.1039/C1CC10237K

All rights reserved. 